\title{
Penerapan Metode Backpropagation Dalam Memprediksi Jumlah Kunjungan Wisatawan Ke Provinsi Nusa Tenggara Barat (NTB)
}

\author{
(The Application of Backpropagation Method to Estimate the Number of Tourist Visit \\ to Nusa Tenggara Barat Province)
}

\author{
Komang Triantita Neti Lestari, Moh. Ali Albar*, Royana Afwani \\ Dept Informatics Engineering, Mataram University \\ Jl. Majapahit 62, Mataram, Lombok NTB, INDONESIA \\ Email: triantitaneti286@gmail.com, mohalialbar@unram.ac.id, royana@unram.ac.id
}

*Penulis korespondensi

\begin{abstract}
Based on the of tourist visits of West Nusa Tenggara from 2013 to 2017 obtained from Tourism Office of NTB Province the number of tourist visits changes every year. a prediction is needed to estimate the number of tourist visits in the upcoming year to help the government in making policy. The Tourism Office currently estimaties the tourist visit based on the events that will be carried out. There are no mathematic calculations in estimations. This study uses Backpropagation to predict the number of tourist visits. Backpropagation is a good and accurate in predicting process involving fluctuating data. This study aims to examine the effectiveness of the backpropagation in predicting the number of tourist visits based on the minimum value of the Mean Square Error (MSE). Using a maximum iteration of 1500 , learning rate 0.3 and the number of hidden layers 21 produces the minimum MSE value of 0.003901 and the prediction of tourist visits in 2018 has the most tourist arrivals in July 2018 of 465.202 tourists and the lowest visit was in February 2018, which estimated to 236.864 tourists.
\end{abstract}

Key words: Prediction, Backpropagation, Tourists Visit, West Nusa Tenggara Province

\section{PENDAhUluan}

Faktor penentu perkembangan pariwisata di Provinsi NTB adalah tingkat kunjungan wisatawan baik nusantara maupun mancanegara. Data jumlah kunjungan wisatawan lima tahun terakhir di Provinsi NTB yakni januari 2013 hingga desember 2017 yang diperoleh dari Dinas Pariwisata Provinsi NTB dimana wisatawan yang berkunjung cenderung mengalami perubahan. Banyaknya wisatawan yang ke Provinsi NTB untuk tahun 2013 adalah 1.357.602 wisatawan yang mengalami peningkatan sebesar $19.9 \%$ pada tahun 2014 yakni sebanyak 1.629 .122 wisatawan. Wisatawan di 2015 meningkat 35.7\% dibandingkan 2014 yakni sebanyak 2.210 .527 wisatawan. Pada 2016 meningkat sebesar 39.9\% dibandingkan 2015 yakni sebanyak 3.094.437 wisatawan, dan yang terakhir di 2017 meningkat kembali sebesar 13.4\% dibandingkan 2016 yakni berjumlah 3.508 .903 wisatawan, sehingga rata-rata peningkatan jumlah kunjungan wisatawan ke
Provinsi NTB dari peningkatan selama periode lima tahun terakhir tersebut adalah sebesar 10.7\%[1].

Berdasarkan data tersebut maka perlu dilakukan suatu prediksi jumlah kunjungan wisatawan ke Provinsi NTB untuk membantu pemerintah terkait dalam menangani lonjakan wisatawan dan dalam proses pengambilan keputusan. Prediksi jumlah kunjungan wisatawan ke Provinsi NTB sudah dilakukan oleh Dinas Pariwisata Provinsi NTB namun hanya berdasarkan pada event yang akan dilaksanankan ke depannya sehingga belum ada penggunaan perhitungan matematis yang mendasari perkiraan tersebut oleh karena itu dalam melakukan prediksi diperlukan penerapan metode dengan tujuan untuk memperkecil kesalahan dalam proses prediksi sehingga lebih akurat atau hampir mendekati nilai aktual. Proses memprediksi jumlah kunjungan wisatawan seperti metode exponential smoothing (ES), autoregressive integrated moving average (ARIMA), seasonal autoregressive integrated moving average (SARIMA) dan Weighted Moving Average (WMA) sudah banyak dimanfaatkan. Kekurangan dari metode statistik di atas adalah jeleknya akurasi dan data memiliki sifat linear [2]. Untuk mengatasinya maka pada penelitian ini digunakan metode Jaringan Syaraf Tiruan (JST) Backpropagation. Metode Backpropagation sangat cocok digunakan untuk data yang bersifat nonlinear seperti data jumlah kunjungan wisatawan yang dapat mengalami fluktuasi setiap tahunnya.

Oleh karena itu, pada penelitian ini digunakan metode JST backpropagation untuk melihat bagaimana tingkat efektifitas dan akurasi dari metode tersebut untuk di terapkan pada proses prediksi jumlah kunjungan wisatawan ke Provinsi NTB dengan menggunakan aplikasi berbasis website dalam memperkirakan dan memprediksi banyaknya kunjungan dan hasil dari sistem ini diharapkan dapat membantu pemerintah terutama yang berkaitan dengan Dinas Pariwisata sebagai bahan pertimbangan dalam proses pengambilan kebijakan untuk pengembangan sektor wisata di Provinsi NTB. 


\section{TINJAUAN PUSTAKA}

Hingga saat ini metode statistik banyak dimanfaatkan untuk prediksi jumlah kunjungan wisatawan pada penelitian sebelumnya [3][4][5]. Dari ketiga penelitian tersebut dapat disimpulkan bahwa prediksi kunjungan wisata dianggap sangat penting karena merupakan suatu faktor penentu terhadap perkembangan sektor wisata yang akan berdampak pada sektor ekonomi masyarakat. Hasil dari ketiga penelitian tersebut antara lain, pada penelitian prediksi kunjungan wisata di Lombok Tengah untuk metode SARIMA didapatkan akurasi nilai Root Mean Square Error (RMSE) sebesar 1133.602, Mean Absolute Error (MAE) sebesar 860.4347 dan Mean Absolute Precentage Error (MAPE) sebesar 16.70765. Prediksi jumlah kunjungan wisatawan ke Uluwatu dengan metode ARIMA diperoleh hasil dengan nilai MSE 32313.95, sedangkan prediksi jumlah wisata di Jatim Park Group pada Kota Wisata Batu untuk metode WMA dilakukan pengujian metode WMA selama 5 tahun. Pengujian ini dibedakan high session dan low session dengan pengukuran Mean Error (ME). Dalam range waktu 3 bulan diperoleh nilai ME sebesar -1918.98 pada low season dan nilai ME sebesar 976.2374 pada high season, dalam range waktu 4 bulan diperoleh nilai ME sebesar 568.0617 pada low season dan ME sebesar 787.1036 pada high season, sedangkan pada range waktu 5 bulan diperoleh nilai ME sebesar 524.608 pada low season dan nilai ME sebesar 746.1027 pada high season.

Beberapa penelitian sudah menggunakan metode Backpropagation untuk prediksi seperti pada kasus prediksi curah hujan, prediksi jumlah permintaan koran, prediksi harga saham, prediksi harga jual kelapa sawit, dan prediksi permintaan produksi[6][7][8][9][10]. Dari kelima penelitian tersebut dapat ditarik kesimpulan bahwa Backpropagation sangat cocok untuk diterapkan pada prediksi. Pada penelitian prediksi curah hujan diperoleh hasil akurasi terbaik pada pengujian jumlah 5 hidden layer dan target error 0.0072 dengan nilai akurasi sebesar $43.27 \%$. Penelitian prediksi jumlah permintaan koran diperoleh hasil pengujian terbaik pada iterasi sebanyak 200 , learning rate 0.6 dan jumlah data training 100 dan data tes 10 dengan MSE sebesar 0.0162. Penelitian prediksi harga saham menggunakan data sebanyak 1235 . yang dibagi menjadi data harga pembuka dan penutup, tertinggi dan terendah, harga emas dan minyak dengan hasil 99,98\% akurat dan MSE 0,9915. Pada penelitian prediksi harga jual kelapa sawit di peroleh hasil pengujian terbaik dengan menggunakan 6 hidden layer dan iterasi maksimum sebanyak 166 menghasilkan nilai MSE sebesar 0.001 , sedangkan pada penelitian prediksi permintaan produksi dengan pengujian 20 lapisan tersembunyi, 0,1 learning rate yang digunakan dan 0,2 nilai konstanta momentum. Hasilnya MSE tahap training 0,001 dan MAPE tahap tes 5,7134\%.

Terdapat penelitian yang menggunakan metode Backpropagation dalam melakukan estimasi wisatawan mancanegara yang data ke Sumatera Utara[11], penelitian tersebut hanya melakukan prediksi terhadap kunjungan wisatawan manacanegara dari tujuh negara Asia Tenggara yakni Brunai Darusalam, Malaysia, Philipina, Singapura, Thailand, Vietnam dan Myanmar. Hal yang diuji yakni parameter hidden layer sebanyak 7, 10, 11, 12, dan 15 dan di peroleh hasil pengujian terbaik pada jumlah 7 hidden layer dengan nilai nilai MSE sebesar 0.006513.

Berdasarkan dari beberapa penelitian yang menjadi tinjauan pustaka tersebut dapat disimpulkan bahwa prediksi jumlah kunjungan wisatawan dengan menggunakan metode statistik masih manghasilkan nilai akurasi yang tidak akurat yang dapat dilihat dari nilai MSE, RMSE, MAPE dan ME yang dihasilkan masih cukup besar, sedangkan metode Backpropagation pada beberapa kasus prediksi menghasilkan nilai MSE yang cukup baik dan akurat, sehingga pada pada penelitian ini dilakukan suatu penelitian yaitu prediksi kunjungan wisata dengan penerapan metode Backpropagation di NTB. Penelitian ini memilih kasus prediksi jumlah kunjungan wisatawan karena kunjungan wisatawan merupakan suatu faktor penentu terhadap perkembangan pariwisata di Provinsi NTB yang sangat berpengaruh pada keadaan ekonomi masyarakat NTB, juga untuk membantu pemerintah terkait dalam proses pengambilan keputusan dan kebijakan. Metode Backpropagation dipilih sebagai metode yang digunakan karena dianggap sangat cocok digunakan untuk data yang bersifat nonlinear seperti data jumlah kunjungan wisatawan yang dapat mengalami fluktuasi setiap tahunnya. Backpropagation memiliki error yang minimum untuk mengenali pola di masa sebelumnya [12]. Data yang dipakai jumlah kunjungan wisatawan dalam periode 5 tahun terakhir yakni 2013 2017 yang dibangun dengan sistem berbasis web. Tujuan penelitian untuk melihat efektifitas prediksi metode backpropagation di NTB.

\section{Metode Penelitian}

\section{A. Data}

Penggunaan datanya bersumber dari Dinas Pariwisata Provinsi NTB. Datanya berupa jumlah kunjungan wisatawan ke Provinsi NTB selama periode lima tahun yakni dari Januari 2013 hingga Desember 2017 sebanyak bulan selama 5 tahun yakni 60 data dimana data tahun 2013-2016 sebanyak 48 data di gunakan sebagai data latih dan datah tahun 2017 sebanyak 12 data di gunakan sebagai data uji yang diperoleh berdasarkan pintu masuk seperti Pelabuhan Lembar, Bandara Internasional, Pelabuhan Fast Boat dan Pelabuhan Sape. Teknik pengambilan data dilakukan dengan melakukan wawancara dengan Staf di Dinas Pariwisata Provinsi NTB.

\section{B. Alur Penelitian}

Alur dari penelitian ini dapat dilihat pada Gambar 1.

1. Studi literatur di sini berupa jurnal, dokumentasi, dan pustaka. Tujuannya agar dapat mengetahui kekurangan dan kelebihan dari berbagai penelitian sebelumnya sehingga dapat digunakan sebagai acuan dalam mengembangkan sistem. 
2. Identifikasi masalah merupakan tahap untuk menentukan daftar permasalahan yang akan dicari solusinya. Input yang dibutuhkan adalah data jumlah kunjungan wisatawan ke Provinsi NTB selama lima tahun dan output yang ingin dihasilkan adalah hasil prediksi jumlah kunjungan pada bulan di tahun berikutnya dan proses apa yang dilakukan untuk menghasilkan output tersebut. Identifikasi masalah dilakukan dengan observasi ke Dinas Pariwisata Provinsi NTB.

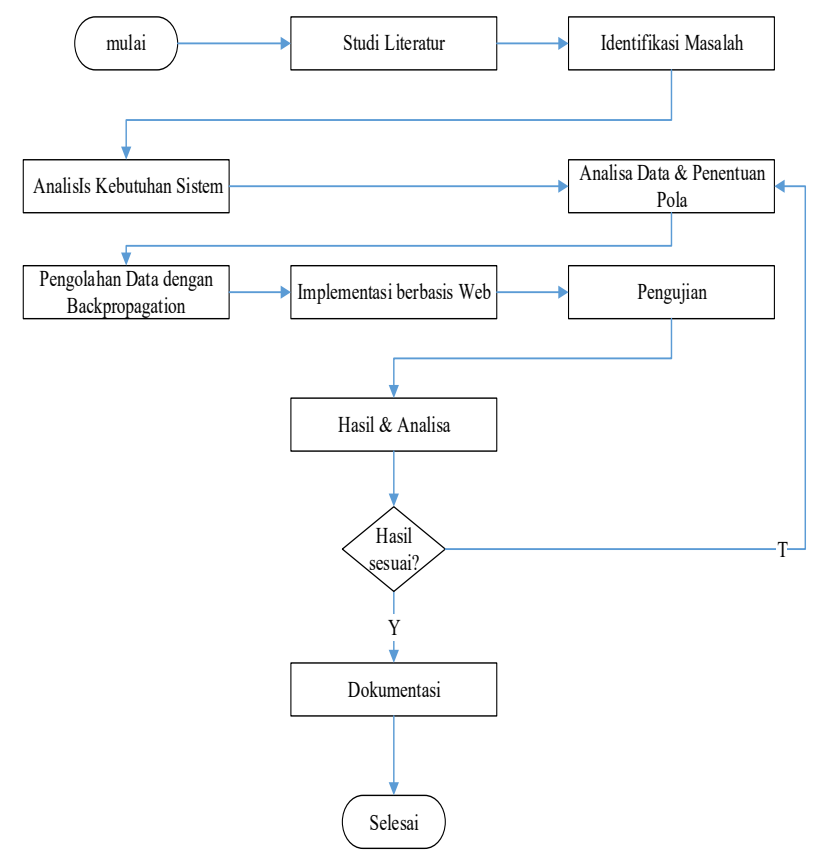

Gambar 1. Diagram Alir

3. Analisa kebutuhan sistem merupakan tahapan untuk menentukan kebutuhan sistem seperti data-data yang dibutuhkan. Tahap ini dilakukan agar sistem yang dihasilkan sesuai dengan tujuan dan tepat sasaran. Hal yang dilakukan Pada tahap ini adalah pengumpulan data dan penjabaran berbagai kebutuhan sistem berupa wawancara ke pihak yang bersangkutan. Untuk penelitian ini dilakukan wawancara dengan Bapak I.Nengah Gusia, SE selaku Staf Jabatan Fungsional di Dinas Pariwisata Provinsi NTB. Wawancara dilakukan dengan tujuan untuk mengetahui bagaimana pola kunjungan wisatawan dengan melihat serta mempelajari data historik jumlah kunjungan wisatawan ke Provinsi NTB selama periode lima tahun terakhir.

4. Analisa data dilakukan untuk mengetahui bagaimana jenis data yang digunakan untuk selanjutnya dapat melakukan penentuan pola yang sesuai dengan data tersebut. Pada data jumlah kunjungan wisatawan ini datanya bersifat nonlinear dan mengalami fluktuasi atau datanya mengalami penurunan dan kenaikan pada bulan-bulan tertentu yang disebabkan oleh beberapa faktor.
5. Setelah data dianalisa dan pola yang tepat sudah ditentukan maka selanjutnya data akan diolah dengan metode backpropagation. Tahapan prediksi dimulai dengan mengambil masukan data, normalisasi, training, tes dan melakukan prediksi yang dapat dilihat pada Gambar 2.

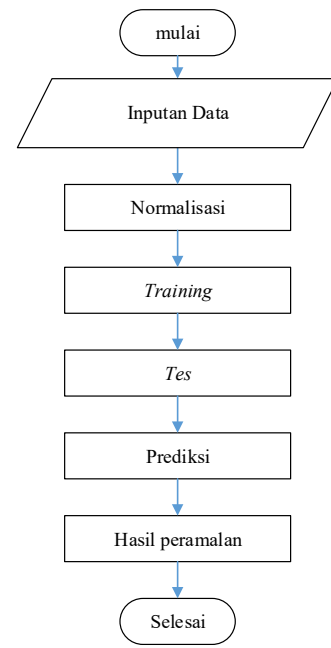

Gambar 2. Flowchar Sistem Backpropagation

Berikut ini adalah penjelasan dari diagram alir penelitian adalah:

1) Masukan Data adalah data jumlah kunjungan wisatawan ke Provinsi NTB selama periode lima tahun terakhir sebanyak 12 data setiap tahunnya. Data di peroleh dari Dinas Pariwisata Provinsi NTB. Penggunaan data sebagai data latih dan uji.

2) Data input melalui preprocessing dengan penskalaan data input untuk standarisasi data agar hasil lebih optimal dalam interval [0,1]. Selain itu digunakan fungsi aktivasi sigmoid biner. Fungsi sigmoid adalah fungsi dengan interval yang lebih kecil yaitu [0.1, 0.9] ditunjukan dalam persamaan 1.

3) Setelah melalui preprocessing data dibagi menjadi data tahun 2013-2016 untuk data latih dan data tahun 2017 untuk data uji. Pemilihan data training lebih banyak dari data testing dikarenakan pada proses training dibutuhkan data yang lebih banyak untuk mendapatkan bobot yang paling baik untuk selanjutnya digunakan pada tahap pengujian.

4) Tahap Pelatihan dilakukan hingga nilai kesalahan sama atau lebih kecil dari targer kesalahan yakni 0.01 . Tahap pelatihan akan menghasilkan bobot baru hingga di dapat bobot terbaik untuk selanjutnya akan digunakan dalam proses pengujian.

5) Tahap pengujian dilakukan untuk menguji validasi data yang telah dilakukan pada tahap pelatihan dengan memasukan data baru yang belum pernah dilatih sebelumnya untuk mengetahui ke akurasian dari sistem yang dibuat. Tahap ini dengan 
mengubah parameter jumlah hidden layer, maksimal iterasi, serta learning rate dengan tujuan mendapat variasi terbaik yang akan digunakan dalam proses prediksi. Setelah didapat hasil prediksi selanjutnya hasil prediksi tersebut akan dibandingkan dengan data aktual untuk melihat tingkat ke akurasiannya. Pengujian dilakukan pada tiga parameter yaitu:

a. Iterasi maximum yang menghasilkan akurasi yang paling baik. Iterasi maksimum yang akan digunakan antara lain 100, 500, 1000, 1500, 2000, 2500 dan 3000

b. Learning rate yang paling baik dengan nilai 0.1 , $0.2,0.3,0.4,0.5,0.6$ dan 0.7

c. Hidden layer sebanyak 3, 9, 15, 21, 27, 30 dan 36

Kemudian untuk menentukan keefektifitasan metode yang digunakan dilakukan dengan melihat tingkat akurasi dengan MSE dari hasil kombinasi ketiga parameter tersebut.

$$
M S E=\frac{\sum_{i=1}^{n}\left(X_{n}-F_{n}\right)^{2}}{n}
$$

Selisih error $=$ nilai data $a_{\text {aktual }}-$ nilai data $a_{\text {prediksi }}$ Persen error $=\frac{\text { nilai dat }_{\text {aktual }}-\text { nilai data }_{\text {prediksi }}}{\text { nilai data }_{\text {aktual }}} \times 100 \%$

6) Tahap prediksi adalah tahap untuk memprediksi atau meramalkan jumlah kunjungan wisatawan ke Provinsi NTB tiap bulan pada satu tahun berikutnya yakni 2018 dengan menggunakan variasi parameter yang terbaik dari hasil pengujian. Setelah mendapat hasil prediksi data akan didenormalisasi atau proses mengubah data hasil normalisasi menjadi data asli. Rumus denormalisasi ditunjukan pada Persamaan (2).

$$
X=\frac{\left(X^{\prime}-0.1\right)(b-a)}{0.8}+a
$$

Keterangan:

$X^{\prime}=$ Nilai data ternormalisasi

$X=$ Data ke-n

$a=$ Data terendah

$b=$ Data tertinggi

6. Data yang sudah diolah dengan menggunakan metode backpropagation selanjutnya akan diimplementasikan ke dalam sebuah sistem berbasis web untuk dilakukan tahap pelatihan, tahap pengujian dan tahap prediksi. Digunakan sebuah sistem berbasis web dengan tujuan agar dapat lebih mudah di akses oleh pihak-pihak yang membutuhkan seperti para investor dan pelaku usaha. Hasil prediksi dari sistem ini nantinya dapat digunakan sebagai referensi dan informasi tambahan sebagai bahan pertimbangan dalam proses pengambilan keputusan.

7. Sistem yang sudah diimplementasi akan dilakukan pengujian hingga sesuai dengan tujuan penelitian. Tahap ini membandingkan nilai prediksi dengan data aktual untuk beberapa parameter seperti jumlah hidden layer, jumlah iterasi dan learning rate.

8. Setelah dilakukan pengujian hasil akan di analisa berdasarkan variasi parameter pada pengujian yang menghasilkan tingkat keakurasian yang paling baik. Proses analisa hasil dari pengujian iterasi maksimum, learning rate dan hidden layer.

9. Apabila hasil sudah sesuai maka langsung dilakukan tahap dokumentasi berupa laporan dan jurnal apabila belum sesuai maka kembali ke tahap analisa data dan penetuan pola.

\section{Diagram Alir Metode Backpropagation}

Gambar 3 adalah alur perhitungan pada metode Backpropagation [13].

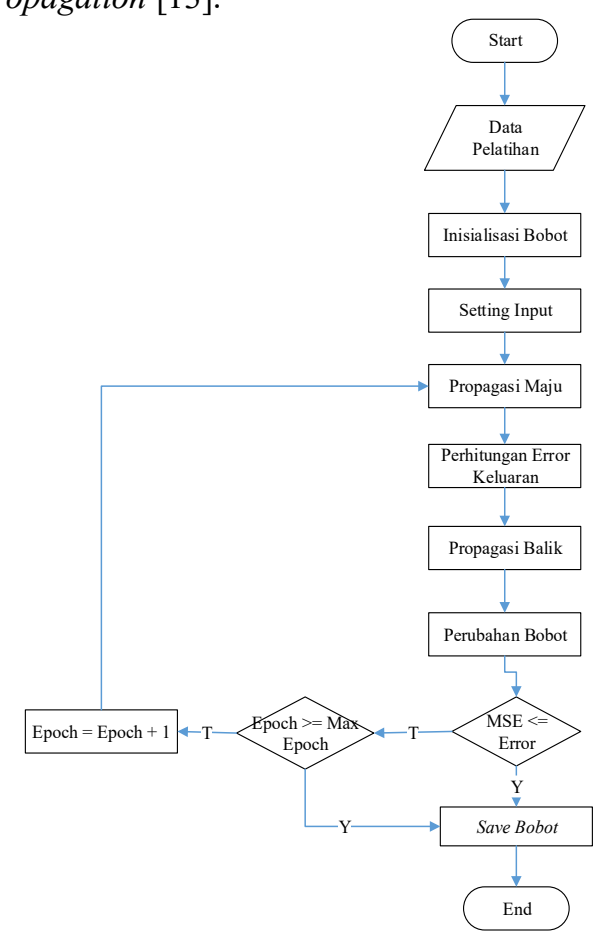

Gambar 3. Metode perhitungan Backpropagation [13]

Berikut ini adalah langkah-langkah pada proses perhitungan menggunakan metode Backpropagation:

1) Langkah 0: Inisialisasi semua bobot dengan bilangan acak kecil. Digunakan fungsi sigmoid biner yakni merupakan fungsi asimtotik (tidak pernah mencapai 0 atau 1) maka transformasi data dilakukan pada interval yang lebih kecil yaitu $[0.1 ; 0.9]$, di tunjukan dengan Persamaan (3)

$$
X^{\prime}=\frac{0.8(x-a)}{b-a}+0.1
$$

dimana:

$X^{\prime}=$ Nilai data ternormalisasi

$X=$ Data ke-n

$a=$ Data terendah

$b=$ Data tertinggi

2) Langkah 1: Jika kondisi penghentian belum terpenuhi, lakukan langkah 2-9. 
3) Langkah 2: Untuk setiap pasangan data pelatihan, lakukan langkah 3-8.

\section{Fase 1: Propagasi Maju}

4) Langkah 3: Tiap input layer menerima sinyal dan meneruskannya ke hidden layer di atasnya.

5) Langkah 4: Hitung semua keluaran di hidden layer $Z_{j}(j=1,2, \ldots, p)$ menggunakan Persamaan (4)

$$
z_{-} n e t_{j}=v_{j 0}+\sum_{i=1}^{n} x_{i} v_{j i}
$$

Dan memakai fungsi aktivasi sigmoid yang telah ditentukan untuk menghitung sinyal output dari hidden layer yang bersangkutan,

$$
z_{j}=f\left(z_{n e t j}\right)=\frac{1}{1+e^{-z_{-} n e t j}}
$$

Lalu mengirim sinyal output ke seluruh layer pada output layer

dimana :

$z_{-}$net $_{j}=$ sinyal input pada hidden layer $\mathrm{ke}-\mathrm{j}$

$v_{j o}=$ bias ke hidden layer $\mathrm{ke}-\mathrm{j}$

$v_{j i}=$ bobot antara input layer $\mathrm{ke}-\mathrm{i}$ dan hidden layer

$\mathrm{ke}-\mathrm{j}$

$x_{i}=$ input layer $\mathrm{ke}-\mathrm{i}$

$z_{j}=$ hidden layer $\mathrm{ke}-\mathrm{j}$

$i=$ urutan input layer

$j=$ urutan hidden layer

$p=$ jumlah maksimum unit pada hidden layer

6) Langkah 5 : Hitung semua keluaran jaringan di layer output $y_{k}, k=1,2,3, \ldots, m$ ) menggunakan Persamaan (6).

$$
y_{-} n e t_{k}=w_{k 0}+\sum_{i=1}^{n} z_{j} w_{k j}
$$

Dan memakai fungsi aktivasi yang telah ditentukan untuk menghitung sinyal output dari output layer yang bersangkutan:

$$
y_{k}=f\left(y_{\text {netk }}\right)=\frac{1}{1+e^{-y_{-n e t k}}}
$$

dimana :

$y_{-}$net $_{k}=$ sinyal masukan output $\mathrm{ke}-\mathrm{k}$

$w_{k 0}=$ bias ke hidden layer $\mathrm{le}-\mathrm{k}$

$w_{k j}=$ output $\mathrm{ke}-\mathrm{k}$ dan hidden layer $\mathrm{ke}-\mathrm{j}$

$z_{j}=$ hidden layer $\mathrm{ke}-\mathrm{j}$.

Fase 2: Propagasi Mundur

7) Langkah 6 : Hitung faktor $\delta$ Setiap output layer dari error tiap output layer $\left(y_{k}, \quad \mathrm{k}=1,2,3, \ldots, \mathrm{m}\right)$ menggunakan Persamaan 8

$$
\begin{aligned}
\delta_{k} & =\left(t_{k}-y_{k}\right) f^{\prime}\left(\text { ynet }_{k}\right) \\
& =\left(t_{k}-y_{k}\right) y_{k}\left(1-y_{k}\right)
\end{aligned}
$$

$\delta_{k}$ merupakan unit kesalahan yang akan digunakan dalam perubahan bobot layer di bawahnya (langkah 7). Faktor $\delta_{k}$ digunakan untuk menghitung koreksi error $\left(\Delta w_{k j}\right)$ yang dipakai untuk memperbarui $w_{k j}$ dengan laju percepatan $\alpha$ dengan Persamaan 9 :

$$
\Delta w_{k j}=\alpha \delta_{k} z_{j}
$$

Faktor $\delta k$ ini kemudian dikirim ke layer depannya Keterangan :

$\delta_{k}=$ faktor koreksi error bobot $w j k$

$t_{k}=$ target output $\mathrm{ke}-\mathrm{k}$

$y_{k}=$ aktivasi output ke $-\mathrm{k}$

$\Delta w_{k j}=$ nilai koreksi error bobot $w k j$

$z_{j}=$ aktivasi hidden layer $\mathrm{ke}-\mathrm{j}$

8) Langkah 7 : Hitung faktor $\delta$ hidden layer berdasarkan kesalahan di setiap hidden layer $(Z j, 1,2,3, \ldots, p)$ menggunakan Persamaan (10)

$$
\delta_{-} n e t_{j}=\sum_{k=1}^{m} \delta_{k} w_{k j}
$$

Faktor $\delta$ hidden layer :

$$
\delta_{j}=\delta_{-} \text {net }_{j} f^{\prime}\left(z_{n e t_{j}}\right)=\delta_{\text {net }_{j}} z_{j}\left(1-z_{j}\right)
$$

Hitung suku perubahan bobot yang akan digunakan untuk proses perubahan bobot :

$$
\Delta v_{j i}=\alpha \delta_{j} x_{i}
$$

dimana :

$\delta$ net $\mathrm{j}=$ bobot hidden layer $\mathrm{ke}-\mathrm{j}$

$\delta_{k}=$ faktor koreksi error bobot $w k j$

$w_{k j}=$ bobot antara output $\mathrm{ke}-\mathrm{k}$ dan hidden layer $\mathrm{ke}-\mathrm{j}$

$\delta_{j}=$ faktor koreksi bobot $v i j$

$z_{j}=$ hidden layer $\mathrm{ke}-\mathrm{j}$

$v_{j i}=$ nilai koreksi error bobot $v j i$

$\alpha=$ laju percepatan (learning rate)

$\delta_{i}=$ faktor koreksi error bobot $v j i$

$x_{i}=$ unit input ke $-\mathrm{i}$

\section{Fase 3: Perubahan Bobot}

9) Langkah 8 : Setiap unit output $\left(y_{k}, k=1,2,3, \ldots, m\right)$ akan memperbarui bias dan bobotnya dengan setiap hidden unit

$$
w_{k j}(\text { baru })=w_{k j}(\operatorname{lama} a)+\Delta w_{k j}
$$

Begitu juga dengan setiap hidden unit akan memperbarui bias dan bobotnya denga setiap unit-unit input.

$$
v_{j i}(\text { baru })=v_{j i}(\operatorname{lama})+\Delta v_{j i}
$$

dimana : 
$w_{k j}($ baru $)=$ bobot baru dari hidden layer menuju output layer

$\Delta w_{k j}($ lama $)=$ bobot lama dari hidden layer menuju output layer

$v_{j i}($ baru $)=$ bobot baru dari hidden layer menuju output layer

$\Delta v_{j i}($ lama $)=$ bobot lama dari hidden layer menuju output layer

10)Langkah 9 : Memeriksa stop condition Jika stop condition telah terpenuhi, maka pelatihan jaringan dapat dihentikan.

\section{HASIL DAN PEMBAHASAN}

\section{A. Hasil}

Hasil dari sistem berupa alur kerja sistem beserta interface dari sistem prediksi jumlah kunjungan wisatawan Provinsi NTB. Sistem prediksi jumlah kunjungan wisatawan ini merupakan bentuk implementasi dari metode Backpropagation yang berbasis web. Implementasi sistem ini meliputi bagian input data wisatawan pada Gambar 4 yang berfungsi untuk menginput-kan data jumlah kunjungan wisatawan yang datang pada periode waktu untuk data training dan data testing untuk memprediksi jumlah kunjungan pada periode selanjutnya. Gambar 5 merupakan halaman proses dapat dilakukan proses pelatihan, pengujian dan prediksi dengan sebelumnya harus meng-input-kan empat parameter yakni batas error yang sudah ditentukan 0.01, learning rate, iterasi dan hidden layer, dan memilih tahun latih dan uji.

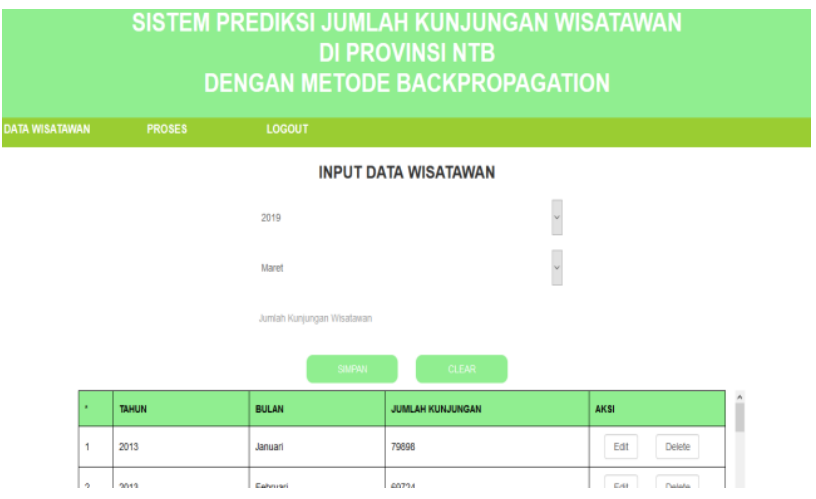

Gambar 4. Halaman Input Data Wisatawan

Gambar 6 memperlihatkan hasil training yakni berupa bobot-bobot terbaik sesuai dengan parameter yang sudah diinput-kan dengan data latih yang sudah ditentukan. Gambar 7 merupakan halaman yang akan menampilkan hasil pengujian dari metode Backpropagation yakni berupa tabel dan grafik perbandingan antara data uji dan data prediksi beserta nilai MSE untuk melihat tingkat akurasi dari prediksi. Gambar 8 merupakan halaman yang akan menampilkan hasil prediksi jumlah kunjungan wisatawan pada tahun berikutnya beserta grafik dari pola kunjungan wisatawan pada tahun tersebut. Proses prediksi menggunakan parameter dengan akurasi terbaik yang di dapat dari proses pengujian.

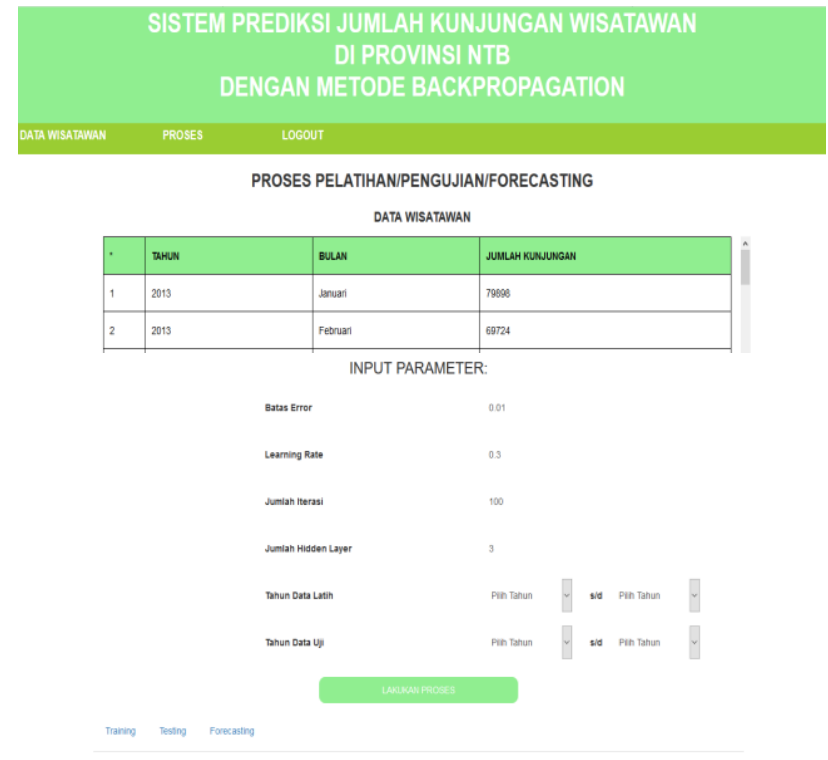

Gambar 5. Halaman Proses

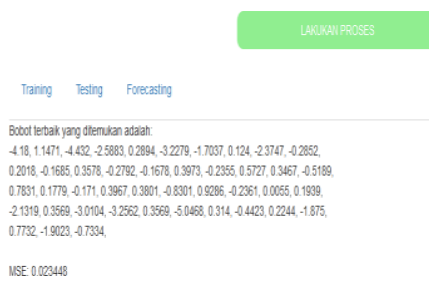

Gambar 6. Halaman Pelatihan/Training

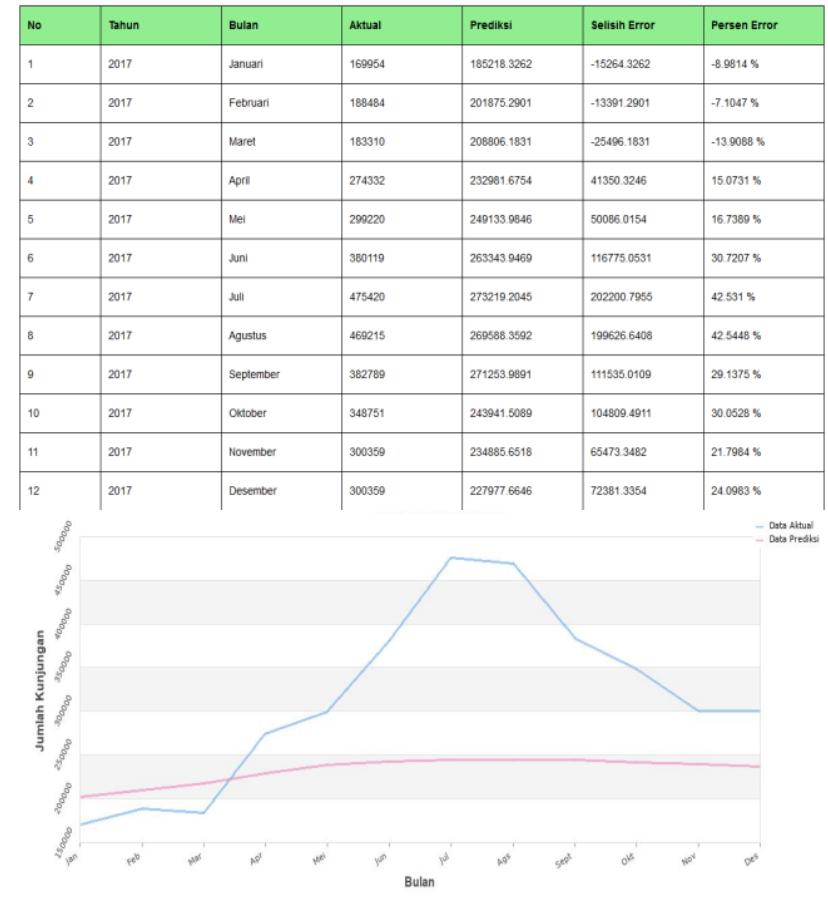

Gambar 7. Halaman Pengujian/Testing 


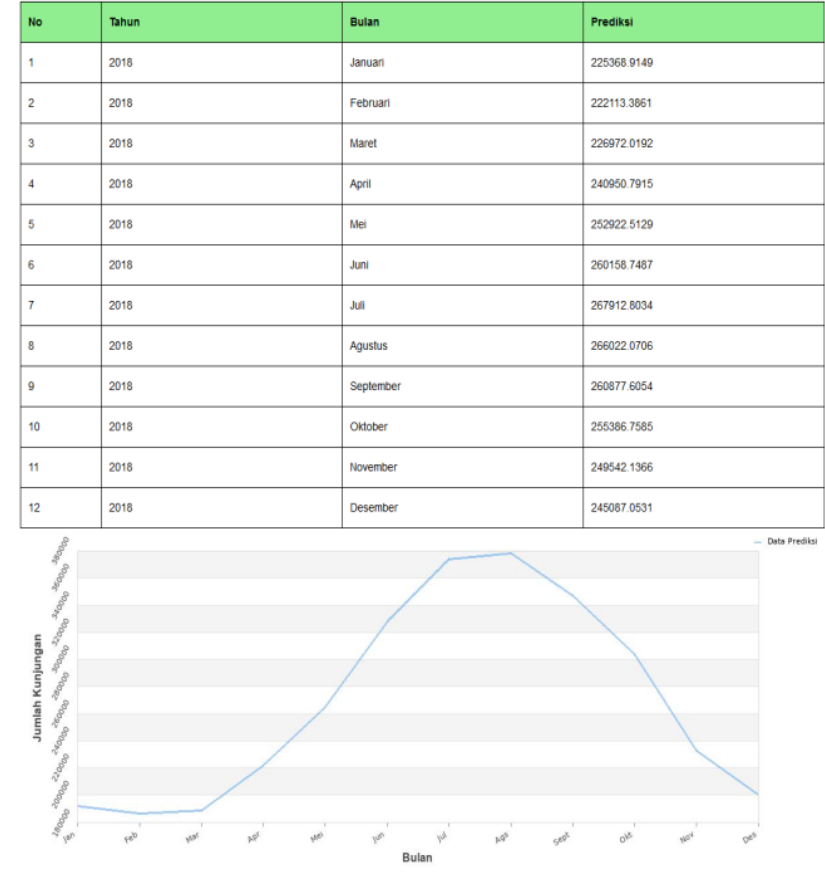

Gambar 8. Halaman Prediksi/Forecasting

\section{B. Pengujian}

Pengujian dilakukan untuk mencari hasil paling optimal dengan menguji beberapa parameter diantaranya learning rate, iterasi maksimum serta hidden layer untuk melihat kondisi terbaik dari parameter-parameter itu untuk digunakan pada proses prediksi di Provinsi NTB dengan data uji tahun 2017 sebanyak 12 data dengan batas error adalah 0.01 dipilih karena semakin kecil batas error maka akan dihasilkan akurasi yang semakin baik.

\section{B.1. Pengujian Iterasi Maksimum}

Tahap ini dilakukan dengan mengubah iterasi maksimum antara 100, 500, 1000, 1500, 2000, 2500 dan 3000. 48 data latih yang diperoleh dari jumlah bulan selama 4 tahun yakni 2013-2016 dan 12 data uji yang diperoleh dari jumlah bulan selama 1 tahun yakni 2017 dengan nilai parameter 0.3 learning rate dan 3 hidden layer. Hasil MSE terkecil atau terbaik pada tahap ini akan digunakan pada proses uji learning rate dan uji hidden layer. Hasil tahap ini terdiri dari tabel yang membandingkan data aktual dan data prediksi dan terdapat hasil perhitungan selisih error, persen error dan nilai MSE yang menjadi acuan tingkat akurasi dari pengujian yang dilakukan.

Berdasarkan Tabel I, maka MSE dari tahap ini di mulai dari 100, 500, 1000, 1500, 2000, 2500 dan 3000 mengalami perubahan di mulai dari iterasi 100 hingga 1500 yakni $0.045586,0.017369,0.013746$ dan 0.013581 dan mengalami kenaikan pada iterasi 2000 hingga 3000 yakni $0.016805,0.016402$ dan 0.063739 .
TABEL I. Hasil Pengujian Iterasi Maksimum Dengan LEARNING RATE 0.3 DAN HIDDEN LAYER 3

\begin{tabular}{|c|c|}
\hline Iterasi Maksimum & MSE \\
\hline 100 & 0.045586 \\
\hline 500 & 0.017369 \\
\hline 1000 & 0.013746 \\
\hline 1500 & 0.013581 \\
\hline 2000 & 0.016805 \\
\hline 2500 & 0.016402 \\
\hline 3000 & 0.063739 \\
\hline
\end{tabular}

Dari hasil pengujian iterasi maksimum menggunakan jumlah iterasi 100, 500, 1000, 1500, 2000, 2500 dan 3000 menunjukan bahwa iterasi maksimum 1500 memberikan hasil terbaik karena MSE yang paling kecil 0.013581. Hal ini membuktikan bahwa nilai akurasi tidak ditentukan oleh semakin banyaknya iterasi. Jumlah iterasi yang digunakan haruslah sesuai, selama kesalahan menurun maka iterasi pelatihan akan terus dijalankan akan tetapi apabila kesalahannya meningkat maka iterasi tidak perlu di teruskan lagi.

\section{B.2. Pengujian Learning Rate}

Tahap ini dilakukan dengan mengubah nilai learning rate dimulai dari $0.1,0.2,0.3,0.4,0.5,0.6$ dan 0.7 .48 data latih yang diperoleh dari jumlah bulan selama 4 tahun yakni 2013-2016 dan 12 data uji diperoleh dari jumlah bulan selama 1 tahun yakni 2017 dengan menggunakan nilai parameter iterasi maksimum terbaik yang didapatkan dari pengujian iterasi maksimum yakni 1500 iterasi dan hidden layer 3. MSE terkecil atau terbaik tahap ini akan digunakan pada tahap uji hidden layer. Hasil tahap ini terdiri dari tabel yang membandingkan data aktual dan data prediksi dan terdapat hasil perhitungan selisih error, persen error dan nilai MSE yang menjadi acuan tingkat akurasi dari pengujian yang dilakukan.

Berdasarkan Tabel II, nilai MSE dari tahap ini di mulai dari $0.1,0.2,0.3,0.4,0.5,0.6$ dan 0.7 mengalami penurunan secara berturut-turut pada 0.1 hingga 0.3 yakni sebesar $0.067670,0.017949$ dan 0.015892 , sedangkan pada 0.4 mengalami kenaikan sebesar 0.061814 dan mengalami penurunan kembali pada 0.5 hingga 0.7 sebesar $0.059929,0.058092$ dan 0.056312 .

TABEL II. Hasil Pengujian Learning Rate Dengan Hidden LAYER 3 DAN ITERASI MAKSIMUM 1500

\begin{tabular}{|c|c|}
\hline Learning Rate & MSE \\
\hline 0.1 & 0.067670 \\
\hline 0.2 & 0.017949 \\
\hline 0.3 & 0.015892 \\
\hline 0.4 & 0.061814 \\
\hline 0.5 & 0.059929 \\
\hline 0.6 & 0.058092 \\
\hline 0.7 & 0.056312 \\
\hline
\end{tabular}

Hasil tahap ini adalah learning rate sebesar $0.1,0.2$, $0.3,0.4,0.5,0.6$ dan 0.7 menunjukan bahwa learning rate 0.3 memberikan hasil terbaik dengan MSE 0.015892. Learning rate merupakan laju pembelajaran untuk 
menurunkan laju iterasinya. Semakin besar learning rate maka semakin cepat pula proses pelatihannya, akan tetapi jika learning rate terlalu besar maka algoritma menjadi tidak stabil dan tidak menghasilkan akurasi yang baik.

\section{B.3. Pengujian Jumlah Hidden Layer}

Tahap ini dilakukan dengan mengubah jumlah layer tersembunyi dimulai dari 3, 9, 15, 21, 27, 30 dan 36. 48 data latih diperoleh dari jumlah bulan selama 4 tahun yakni 2013-2016 dan 12 data uji diperoleh dari jumlah bulan selama 1 tahun yakni 2017 dengan menggunakan nilai parameter iterasi maksimum terbaik yang didapatkan dari pengujian iterasi maksimum yakni 1500 iterasi dan learning rate terbaik pada tahap ini 0.3. Nilai MSE terkecil atau terbaik pada pengujian hidden layer atau pengujian terakhir ini akan digunakan dalam proses prediksi jumlah kunjungan wisatawan di tahun berikutnya. Hasil pengujian terdiri dari tabel yang membandingkan data aktual dan data prediksi dan terdapat hasil perhitungan selisih error, persen error dan nilai MSE yang menjadi acuan tingkat akurasi dari pengujian yang dilakukan.

Berdasarkan Tabel III, nilai MSE dari hasil pengujian hidden layer mulai dari 3, 9, 15, 21, 27, 30 dan 36 mengalami penurunan secara berturut-turut pada hidden layer 3 hingga 21 yakni sebesar 0.018198, 0.004713, 0.004471 dan 0.003901 , dan mengalami kenaikan pada jumlah hidden layer 27, 30 dan 36 yakni 0.007201, 0.006958 dan 0.011104

TABEL III. HASIL PENGUJIAN HIDDEN LAYER DENGAN ITERASI MAKSIMUM 1500 DAN LEARNING RATE 0.3

\begin{tabular}{|c|c|}
\hline Hidden Layer & MSE \\
\hline 3 & 0.018198 \\
\hline 9 & 0.004713 \\
\hline 15 & 0.004471 \\
\hline 21 & 0.003901 \\
\hline 27 & 0.007201 \\
\hline 30 & 0.006958 \\
\hline 36 & 0.011104 \\
\hline
\end{tabular}

Dari hasil pengujian menggunakan hidden layer 3, 9, 15, 21, 27, 30 dan 36 menunjukan bahwa hidden layer 21 memberikan hasil terbaik karena menghasilkan MSE yang paling kecil yakni sebesar 0.003901 . Sering kali pelatihan lebih mudah dilakukan dengan menambahkan jumlah layer tersembnyi namun terlalu banyak jumlah hidden layer belum tentu dapat menghasilkan error yang lebih sedikit.

Jadi dapat disimpulkan bahwa dengan jumlah iterasi sebanyak 1500, 0.3 learning rate, dan 21 jumlah layer tersembunyi merupakan variasi dari ketiga parameter yang terbaik karna menghasilkan nilai MSE yang paling kecil, maka variasi dari ketiga parameter tersebut akan digunakan dalam proses selanjutnya yakni proses prediksi satu tahun berikutnya yakni tahun 2018. Grafik perbandingan data aktual dan data prediksi dari hasil pengujian menggunakan jumlah iterasi 1500, 0.3 learning rate dan 21 layer tersembunyi dengan MSE 0.003901 dapat dilihat pada Gambar 9.

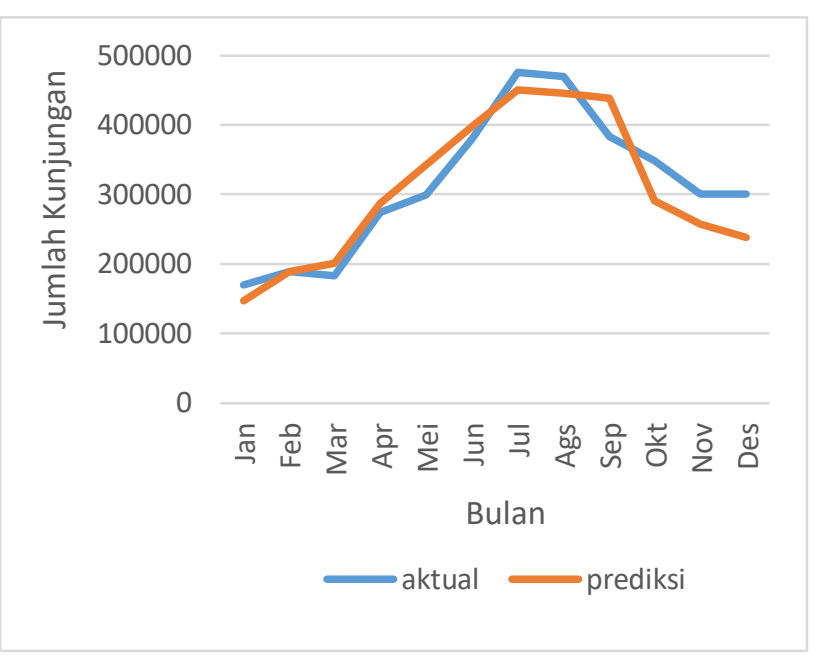

Gambar 9. Grafik Data Prediksi dan Aktual

Pada Gambar 9 dapat di lihat bahwa perbedaan antara nilai aktual dan prediksi memiliki selisih error yang minimal atau data prediksi hampir mendekati nilai aktual, sehingga dapat di simpulkan bahwa proses pelatihan dan pengujian sudah mendapatkan hasil yang baik dan dapat digunakan pada tahap prediksi pada tahun berikutnya yakni 2018.

\section{Prediksi Jumlah Kunjungan Wisatawan}

Proses prediksi jumlah kunjungan wisatawan dilakukan dengan menggunakan variasi parameter terbaik yakni jumlah iterasi sebanyak 1500, 0.3 learning rate dan 21 jumlah layer tersembunyi. Hasil prediksi adalah perkiraan jumlah kunjungan wisatawan pada satu tahun berikutnya yakni tahun 2018 sesuai Tabel 4 dan grafik pola kunjungan dapat dilihat pada Gambar 10.

TABEL IV. HASIL PREDIKSI JUMLAH KUNJUNGAN WiSATAWAN PROVINSI NTB 2018

\begin{tabular}{|c|c|c|c|}
\hline NO & Tahun & Bulan & $\begin{array}{c}\text { Jumlah } \\
\text { Kunjungan }\end{array}$ \\
\hline 1 & 2018 & Januari & 244786 \\
\hline 2 & 2018 & Februari & 236864 \\
\hline 3 & 2018 & Maret & 249848 \\
\hline 4 & 2018 & April & 340404 \\
\hline 5 & 2018 & Mei & 391562 \\
\hline 6 & 2018 & Juni & 445319 \\
\hline 7 & 2018 & Juli & 465202 \\
\hline 8 & 2018 & Agustus & 458528 \\
\hline 9 & 2018 & September & 430305 \\
\hline 10 & 2018 & Oktober & 397235 \\
\hline 11 & 2018 & November & 328138 \\
\hline 12 & 2018 & Desember & 268167 \\
\hline
\end{tabular}

Pada Tabel IV dapat dilihat grafik pola kunjungan di 2018, yaitu pada bulan januari sebesar 244.786 wisatawan yang mengalami penurunan dibandingkan Februari sebesar 236.864 wisatawan. Sedangkan Maret hingga Juli terjadi peningkatan kembali 249.845 wisatawan pada bulan Maret, 340.404 wisatawan pada bulan April, 
391.562 wisatawan pada bulan Mei, 445.319 wisatawan pada bulan Juni dan 465.202 pada bulan Juli, pada bulan Agustus hingga Desember jumlah kunjungan wisatawan ke Provinsi NTB kembali mengalami penurunan yakni sebesar 458.528 wisatawan pada bulan Agustus, 430.305 wisatawan pada bulan September, 397.235 wisatawan pada bulan Oktober, 328.138 wisatawan pada bulan November dan 268.167 wisatawan pada bulan Desember. Jadi pada garfik pola kunjungan wisatawan pada Gambar 4.30 dapat dilihat bahwa kunjungan wisatawan terbesar atau terbanyak ke Provinsi NTB terdapat pada bulan Juli 2018 yakni sebesar 465.202 wisatawan dan kunjungan terendah terdapat pada bulan Februari 2018 sebesar 236.864 wisatawan.

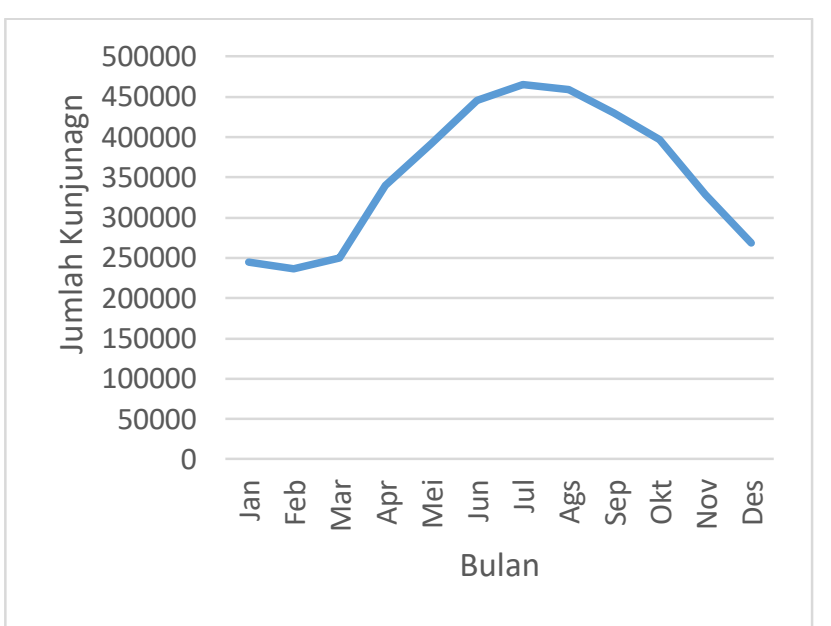

Gambar 10. Pola Kunjungan Wisatawan ke Provinsi NTB tahun 2018

\section{KESIMPULAN DAN SARAN}

\section{A. Kesimpulan}

Hasil yang cukup baik didapatkan dari Backpropagation memberikan hasil yang cukup baik dan memuaskan dalam proses prediksi jumlah kunjungan wisatawan ke Provinsi NTB sebagai bahan pertimbangan dalam proses pengambilan keputusan pihak-pihak terkait. Berdasarkan hasil penelitian tentang prediksi jumlah kunjungan wisatawan ke Provinsi NTB dimulai dari tahap pengembangan sistem maka dapat di peroleh beberapa kesimpulan sebagai berikut:

1. Pengujian menggunakan tiga parameter yakni iterasi maksimum, learning rate dan hidden layer di peroleh hasil yang terbaik adalah dengan menggunakan iterasi maksimum 1500, 0.3 learning rate dan 21 layer tersembunyi dengan MSE 0.003901.

2. Prediksi jumlah kunjungan wisatawan ke Provinsi NTB dengan data yang mengalami fluktuasi setiap bulannya dengan menggunakan metode Backpropagation dapat memprediksi yang baik dengan MSE 0.003901 yang mendekati 0 yakni sehingga metode Bakpropagation ini cukup efektif untuk digunakan pada kasus prediksi.

3. Hasil prediksi ini di Provinsi NTB pada tahun 2018 dapat diketahui bahwa kunjungan wisatawan mengalami peningkatan terbesar pada bulan Juli 2018 sebesar 465.202 wisatawan dan kunjungan terendah terdapat pada bulan Februari 2018 yakni sebesar 236.864 wisatawan.

4. Mengacu pada hasil pengujian dan prediksi yang cukup baik sistem ini sehingga dapat sebagai bahan pertimbangan dalam proses pengambilan keputusan pada kasus prediksi jumlah kunjungan wisatawan ke Provinsi NTB

5. Belum tentunya menghasilkan nilai prediksi yang sama untuk parameter dan data pembelajaran yang sama dikarenakan nilai bobot setiap melakukan pelatihan di acak secara random sehingga nilai bobot yang digunakan akan berbeda-beda.

\section{B. Saran}

Adapun saran dari penelitian ini sebagai berikut:

1. Adanya tindakan lebih lanjut mengenai data untuk prediksi agar lebih akurat, hal ini dirasa perlu dilakukan karena adanya faktor-faktor lainnya yang mempengaruhi jumlah kunjungan wisatawan seperti event-event yang diadakan di Provinsi NTB setiap bulannya dan faktor pendukung lainnya, dimana faktor event tersebut nantinya dapat dijadikan variabel baru pada proses perhitungan di metode Backpropagation.

2. Adanya usaha penambahan data sehingga proses pelatihan menjadi lebih akurat.

3. Menambah parameter masukan pada tahap pelatihan dan pengujian yang dilakukan.

\section{REFERENSI}

[1] I.N. Gusia, "Interview, Wawancara Jumlah Pola Kunjungan Wisata”. Dinas Pariwisata Provinsi NTB, Provinsi NTB, 2018.

[2] Z. Arifin, Kridalaksana, dkk, "Prediksi Kedatangan Turis Asing ke Indonesia Menggunakan Backpropagation Neural Network", Jurnal Teknologi dan Sistem Komputer, 2016.

[3] S.R. Ainy, "Peramalan Jumlah Kunjungan Wisatawan Mancanegara Di Kabupaten Lombok Tengah Pada Tahun 2010-2015 Menggunakan Metode Seasonal Autoregressive Integrated Moving Average (SARIMA)", Fakultas Matematika dan Ilmu Pengetahuan Alam Universitas Islam Indonesia, 2016.

[4] T.T. Sukraini, "Peramalan Kunjungan Wisatawan Ke Uluwatu Dengan Menggunakan Model Autoregressive Integrated Moving Average (ARIMA)", Jurusan Administrasi Niaga Politeknik Negeri Bali, 2016.

[5] Y.L. Saputra, Ekojono, "Sistem Informasi Prediksi Jumlah Wisatawan Pada Jawa Timur Park Group Kota Wisata Batu Menggunakan Metode Forecasting", Program Studi Teknik Informatika, Jurusan Teknologi Informasi, Politeknik Negeri Malang, 2016.

[6] Y. Andrian, E. Ningsih, "Prediksi Curah Hujan di Kota Medan Menggunakan Metode 
Backpropagation Neural Network”, Medan: Teknik Informatika Potensi Utama, 2014.

[7] N.P. Sakinah, I. Cholissodin, W.A. Widodo, "Prediksi Jumlah Permintaan Koran Menggunakan Metode Jaringan Syaraf Tiruan Backpropagation”, Malang: Program Studi Teknik Informatika, Fakultas Ilmu Komputer, Universitas Brawijaya, 2018.

[8] A. Triyono, A.J. Santoso, Pranowo, "Penerapan Metode Jaringan Syaraf Tiruan Backpropagation Untuk Meramalkan Harga Saham (IHSG)", Magister Teknik Informatika, Universitas Atma Jaya Yogyakarta, 2015.

[9] S. Andriyani, Sitohang, Norenta, "Implementasi Metode Backpropagation Untuk Memprediksi Harga Jual Kelapa Sawit Berdasarkan Kualitas Buah", Jurnal Teknologi dan Sistem Informasi, Vol. IV No. 2, hlm. 155 - 164, STMIK Royal, 2018.

[10] M. Febrina, F. Arina, Ekawati, Ratna, "Peramalan Jumlah Permintaan Produksi Menggunakan Metode
Jaringan Syaraf Tiruan Backpropagation”, Jurusan Teknik Industri Universitas Sultan Ageng Tirtayasa, 2013.

[11] E.R. Pranata, Sinaga, S. Palentino, Wanto, Anjar, "Estimasi Wisatawan Mancanegara yang Datang ke Sumatera Utara Menggunakan Jaringan Syaraf", Program Studi Teknik Informatika, STIKOM Tunas Bangsa Pematangsiantar, 2018.

[12] C. Oktaviani, Afdal, "Prediksi Curah Hujan Bulanan Menggunakan Jaringan Syaraf Tiruan dengan Beberapa Fungsi Pelatihan Backpropagation", Jurnal Fisika Unand, 2013.

[13] J.J. Siang, "Jaringan Syaraf Tiruan dan Pemrogramannya menggunakan MATLAB", Yogyakarta: Andi, 2009. 